\title{
Ionic Liquids Applied to Improve the Dispersion of Coagent Particles in an Elastomer
}

\author{
Magdalena Maciejewska and Marian Zaborski \\ Institute of Polymer and Dye Technology, Technical University of Lodz, Stefanowskiego 12/16, 90-924 Lodz, Poland \\ Correspondence should be addressed to Magdalena Maciejewska; magdalena.maciejewska@p.lodz.pl
}

Received 31 January 2013; Revised 25 March 2013; Accepted 25 March 2013

Academic Editor: Zhiping Luo

Copyright ( 2013 M. Maciejewska and M. Zaborski. This is an open access article distributed under the Creative Commons Attribution License, which permits unrestricted use, distribution, and reproduction in any medium, provided the original work is properly cited.

\begin{abstract}
The aim of this work was to study the activity of several ionic liquids (alkylimidazolium salts) that are used to improve the dispersion of coagent particles in peroxide-cross-linked hydrogenated acrylonitrile butadiene elastomer (HNBR). Hydrotalcite grafted with monoallyl maleate was applied as a coagent for the HNBR vulcanization. In this paper, we discuss the effect of the ionic liquids (alkylimidazolium salts) with respect to their anion (bromide, chloride, tetrafluoroborate, and hexafluorophosphate) and the length of alkyl chain in the cation (allyl-, ethyl-, butyl-, hexyl-, and octyl-) on the vulcanization kinetics of rubber compounds. The influence of ionic liquids on the cross-link density, the mechanical properties of the vulcanizates, and their resistance to weather ageing were also studied. Alkylimidazolium salts seem to improve the dispersion of the coagent particles and to be active in the cross-linking of HNBR with peroxide. The type of ionic liquid considerably influences the activity of the coagent particles toward the HNBR. The application of ionic liquids increases the cross-link density of the vulcanizates and improves their resistance to weather aging.
\end{abstract}

\section{Introduction}

Ionic liquids (ILs) are generally defined as salts with melting points below $100^{\circ} \mathrm{C}[1,2]$. The definition of ILs clearly distinguishes them from other molten salts. Research on ILs has been one of the most rapidly growing fields in chemistry and industry in recent years. This rapid growth is mainly due to the many unique properties of ionic liquids. They are able to solvate a large variety of polar and nonpolar organic compounds and show potentially "environmentally friendly" characteristics (negligible vapor pressure, flammability) [3]. Their chemical and physical properties can be tuned for a wide range of potential applications by varying the cations and anions. The antielectrostatic properties of ILs have also been recognized [3]. In the past few years, ILs not only have been employed as solvents for various types of polymerization $[4,5]$ but also have been used to dissolve polymers $[6,7]$, to impart functionality and to create new polymer composites [8]. Applications of ILs as solvents for polymerization processes, as components of polymeric matrices (such as polymer gels), as templates for porous polymers, and as novel electrolytes for electrochemical polymerizations have been reviewed $[9,10]$. However, the application of ILs to improve the dispersion of coagents based on hydrotalcite for elastomer cross-linking with peroxides has not yet been reported. Thus, this work represents an innovative solution.

Coagents are applied to improve the physical properties and processing of peroxide-cross-linked elastomers. Coagent application allows for the generation of materials with higher tensile and tear strengths, higher modulus and hardness values, and better abrasion resistance and adhesion to metal $[11,12]$. Most coagents are relatively polar compounds, which are difficult to mix with nonpolar polymers. Despite being homogeneously dispersed in a polymer matrix, coagent molecules can agglomerate again, form domains, and then homopolymerize [13]. The polymerized coagent domains are most likely covalently bonded to the surrounding polymer matrix [14]. Commonly used coagents for cross-linking of polymers are diallyl terephthalate, triallyl cyanurate, and zinc acrylates. They are incorporated into the polymer network because of the covulcanization of their domains with the surrounding polymer matrix [15]. However, the use of 
these coagents has one major disadvantage that restricts their industrial application: deterioration of the mechanical properties of the vulcanizates. This is most likely due to the presence of rigid aromatic structures of coagent molecules, which form hard domains during vulcanization that are strongly bonded to the surrounding "soft" elastomer. Stress is then concentrated near the hard coagent domains, which leads to the destruction of the sample upon deformation [16]. Recently, we reported the high activity of hydrotalcite grafted with monoallyl maleate as the coagent in the peroxide cross-linking of saturated elastomer [17]. The application of this coagent allowed for the realization of vulcanizates with considerably improved mechanical properties and a higher cross-link density compared with vulcanizates crosslinked only with peroxide. However, the ionic cross-link content and tensile strength of vulcanizates decreased with the increase in the amount of coagent in the elastomer because of the agglomeration of the coagent particles in the elastomer. Therefore, it is necessary to develop a substance to improve the dispersion of coagent particles in the elastomer. We applied long-chain ILs with different numbers of alkyl groups to improve the dispersion of the coagent. It is believed that ILs could polymerize during vulcanization and create a structure in the elastomer composed of soft domains of in situpolymerized IL, similar to the mechanism proposed by Lu et al. [18] for interactions between a polar elastomer and zinc dimethacrylate. A structure consisting of poly-IL domains could be deformed upon the application of external stresses, improving the mechanical strength of the material. It is also possible that ILs could participate in the formation of additional noncovalent cross-links in the elastomer network. Elastomer composites with this type of morphology should reveal the ability to relax stress upon external deformation of the sample. The ability of imidazolium salts containing vinyl groups covalently introduced on IL cation or anion moieties to facilitate polymerization has been confirmed [19, 20]. Moreover, its application was shown to improve silica dispersions in elastomers and the mechanical performance of the vulcanizates. The positive effect of ILs on the dispersion of zinc oxide in the elastomer and the mechanical properties of vulcanizates was also confirmed [21].

In this work, we employed hydrotalcite grafted with monoallyl maleate (HTA/MMA) as a coagent for the crosslinking of HNBR with dicumyl peroxide. This method allowed hydrotalcite to act as the filler and coagent simultaneously. To improve the dispersion of HTA/MMA particles in the elastomer, ILs (alkylimidazolium salts) were applied. The influence of ILs on the cure kinetics of rubber compounds and their cross-linking efficiency, vulcanizate crosslink density, tensile strength, and resistance to weather aging was discussed.

\section{Experimental Section}

2.1. Materials. Hydrogenated acrylonitrile-butadiene elastomer HNBR (Therban A3407) containing 34 wt\% acrylonitrile was obtained from Bayer Co. The Mooney viscosity was $\left(\mathrm{ML1}+4\left(100^{\circ} \mathrm{C}\right): 70\right)$. It was vulcanized with dicumyl peroxide DCP (Aldrich). Synthetic hydrotalcite (HTA, Aldrich)
TABLE 1: Characteristics of ionic liquids (ILs).

\begin{tabular}{|c|c|c|}
\hline ILs & Producer & Symbol \\
\hline 1-allyl-3-methylimidazolium bromide & Aldrich & $\mathrm{AMIBr}$ \\
\hline 1-ethyl-3-methylimidazolium bromide & Aldrich & $\mathrm{EMIBr}$ \\
\hline 1-butyl-3-methylimidazolium bromide & Aldrich & $\mathrm{BMIBr}$ \\
\hline 1-allyl-3-methylimidazolium chloride & Aldrich & $\mathrm{AMICl}$ \\
\hline 1-ethyl-3-methylimidazolium chloride & Aldrich & EMICl \\
\hline 1-butyl-3-methylimidazolium chloride & Aldrich & $\mathrm{BMICl}$ \\
\hline 1-hexyl-3-methylimidazolium chloride & Aldrich & $\mathrm{HMICl}$ \\
\hline $\begin{array}{l}\text { 1-ethyl-3-methylimidazolium } \\
\text { tetrafluoroborate }\end{array}$ & Aldrich & $\mathrm{EMIBF}_{4}$ \\
\hline $\begin{array}{l}\text { 1-butyl-3-methylimidazolium } \\
\text { tetrafluoroborate }\end{array}$ & Aldrich & $\mathrm{BMIBF}_{4}$ \\
\hline $\begin{array}{l}\text { 1-hexyl-3-methylimidazolium } \\
\text { tetrafluoroborate }\end{array}$ & Aldrich & $\mathrm{HMIBF}_{4}$ \\
\hline $\begin{array}{l}\text { 1-methyl-3-octylimidazolium } \\
\text { tetrafluoroborate }\end{array}$ & Aldrich & $\mathrm{OMIBF}_{4}$ \\
\hline $\begin{array}{l}\text { 1-ethyl-3-methylimidazolium } \\
\text { hexafluorophosphate }\end{array}$ & Aldrich & $\mathrm{EMIPF}_{6}$ \\
\hline $\begin{array}{l}\text { 1-butyl-3-methylimidazolium } \\
\text { hexafluorophosphate }\end{array}$ & Aldrich & $\mathrm{BMIPF}_{6}$ \\
\hline $\begin{array}{l}\text { 1-hexyl-3-methylimidazolium } \\
\text { hexafluorophosphate }\end{array}$ & Aldrich & $\mathrm{HMIPF}_{6}$ \\
\hline
\end{tabular}

with the molecular formula $\mathrm{Mg}_{6} \mathrm{Al}_{2}\left(\mathrm{CO}_{3}\right)(\mathrm{OH})_{16} \cdot 4 \mathrm{H}_{2} \mathrm{O}$ was grafted with monoallyl maleate (MMA, Technical University of Lodz) with the procedure described previously [22]. The characteristics of the ionic liquids applied are presented in Table 1.

\subsection{Preparation and Characterization of Rubber Compounds.} Rubber compounds containing $100 \mathrm{phr}$ of HNBR, $2 \mathrm{phr}$ of dicumyl peroxide, $5 \mathrm{phr}$ of coagent (HTA/MMA), and $1.5 \mathrm{phr}$ of IL were prepared using a laboratory two-roll mill. The samples were cured at $160^{\circ} \mathrm{C}$ until they developed a $90 \%$ increase in torque, which was measured by an oscillating disc rheometer. The kinetics of rubber compound vulcanization was studied using a DSC1 (Mettler Toledo) analyzer by decreasing the temperature from 25 to $-60^{\circ} \mathrm{C}$ at a rate of $10^{\circ} \mathrm{C} / \mathrm{min}$ and then heating to $250^{\circ} \mathrm{C}$ with the same heating rate.

The cross-link density $\left(\nu_{T}\right)$ of the vulcanizates was determined by their equilibrium swelling in toluene based on the Flory-Rehner equation [23]. The Huggins parameter of the elastomer-solvent interaction $(\chi)$ was calculated from the equation

$$
\chi=0.501+0.273 V_{r} \text {. }
$$

See [22], where $V_{r}$ is the volume fraction of the elastomer in the swollen gel. To determine the content of noncovalent cross-links in the elastomer network, samples were swollen in toluene in a desiccator with saturated ammonia vapor 
(25\% aqueous solution). The content of noncovalent crosslinks $(\Delta v)$ was calculated from (2), where $\nu_{A}$ is the cross-link density determined for samples treated with ammonia vapor:

$$
\Delta v=\frac{v_{T}-v_{A}}{v_{T}} \cdot 100 \%
$$

The tensile properties and stress relaxation tests of the vulcanizates were measured according to ISO-37 using a ZWICK 1435 universal machine. The strain rate of tensile tests was $500 \mathrm{~mm} / \mathrm{min}$. To determine the stress relaxation properties, a sample was subjected to prolonged constant tension at a constant temperature. Deformation was recorded at specified time intervals $(0-10 \mathrm{~s}, 10-100 \mathrm{~s}$, and 100-1000 s), and a stress relaxation versus time diagram was plotted. The slope of the curve at any point was the stress relaxation rate.

The dispersion of the coagent in the elastomer matrix was estimated using Scanning Electron Microscopy with a ZEISS SEM. The vulcanizates were broken down in liquid nitrogen, and the surfaces of their fractures were examined. Prior to the measurements, the samples were coated with carbon.

The aging of vulcanizates under weather conditions was carried out for 100 hours with an Atlas CI 4000 "Xenon Arc Weather-Ometer" instrument. The aging process followed a simulated day-night cycle with the following parameters: day (102 minutes, irradiation of $60 \mathrm{~W} / \mathrm{m}^{2}, 367 \mathrm{~kJ}$, humidity $50 \%$, spray, temperature: black panel $80^{\circ} \mathrm{C}$, panel chamber $38^{\circ} \mathrm{C}$ ); night (18 minutes, irradiation $60 \mathrm{~W} / \mathrm{m}^{2}, 64 \mathrm{~kJ}$, humidity $5 \%$, no spray, temperature: black panel $80^{\circ} \mathrm{C}$, panel chamber $38^{\circ} \mathrm{C}$ ). To estimate the resistance of the samples to weather aging, their mechanical properties and cross-link density after aging were determined and compared with the values obtained for the composites before aging. An aging factor $(K)$ was calculated as the numerical change in the mechanical properties of the samples upon aging (3):

$$
K=\frac{(\mathrm{TS} \cdot \mathrm{EB})_{\text {after aging }}}{(\mathrm{TS} \cdot \mathrm{EB})_{\text {before aging }}}
$$

\section{Results and Discussion}

3.1. Cure Characteristics and Cross-Link Density of Vulcanizates. The influence of ILs (alkylimidazolium salts) on the vulcanization process was estimated based on rheometer measurements. The cure characteristics of HNBR compounds and cross-link densities of vulcanizates are given in Table 2.

The rubber compound cross-linked only with dicumyl peroxide and the coagent. Without the addition of ILs, the rubber compound was characterized by an increase of torque during vulcanization of approximately $40 \mathrm{dNm}$. The application of ILs did not considerably affect the torque increment compared with the reference rubber compound. There was no correlation between the torque increment and the structure of the cation or anion in the IL molecules.

The ILs had a catalytic effect on the vulcanization process. The vulcanization time of HNBR compounds decreased to as little as 25 minutes when EMICl, BMICl, $\mathrm{HMIBF}_{4}$, and $\mathrm{BMIPF}_{6}$ were present.
TABLE 2: Cure characteristics and cross-link density of HNBR

\begin{tabular}{|c|c|c|c|c|c|}
\hline ILs & $\begin{array}{c}\Delta G \\
(\mathrm{dNm})\end{array}$ & $\begin{array}{c}t_{90} \\
(\mathrm{~min})\end{array}$ & $\begin{array}{c}t_{p} \\
(\mathrm{~min})\end{array}$ & $\begin{array}{c}v_{T} * 10^{-4} \\
\left(\mathrm{~mol} / \mathrm{cm}^{3}\right)\end{array}$ & $\begin{array}{l}\Delta v \\
(\%)\end{array}$ \\
\hline- & 40.6 & 35 & 183 & 29.5 & 10.3 \\
\hline $\mathrm{AMIBr}$ & 38.9 & 35 & 182 & 24.4 & 8.3 \\
\hline EMIBr & 44.3 & 30 & 184 & 36.4 & 10.4 \\
\hline $\mathrm{BMIBr}$ & 39.3 & 30 & 194 & 35.6 & 10.1 \\
\hline $\mathrm{AMICl}$ & 38.9 & 30 & 170 & 24.0 & 8.2 \\
\hline $\mathrm{EMICl}$ & 39.2 & 30 & 170 & 35.6 & 16.6 \\
\hline $\mathrm{BMICl}$ & 36.7 & 25 & 192 & 35.5 & 14.6 \\
\hline $\mathrm{HMICl}$ & 37.3 & 30 & 188 & 34.9 & 16.6 \\
\hline $\mathrm{EMIBF}_{4}$ & 42.8 & 30 & 186 & 40.9 & 18.3 \\
\hline $\mathrm{BMIBF}_{4}$ & 41.7 & 25 & 162 & 34.8 & 10.9 \\
\hline $\mathrm{HMIBF}_{4}$ & 43.7 & 25 & 162 & 32.4 & 13.9 \\
\hline $\mathrm{OMIBF}_{4}$ & 45.6 & 30 & 182 & 26.3 & 18.6 \\
\hline $\mathrm{EMIPF}_{6}$ & 42.9 & 32 & 204 & 36.0 & 14.4 \\
\hline $\mathrm{BMIPF}_{6}$ & 38.3 & 25 & 168 & 35.0 & 12.6 \\
\hline $\mathrm{HMIPF}_{6}$ & 41.7 & 28 & 188 & 34.9 & 12.9 \\
\hline
\end{tabular}
vulcanizates containing ILs.

$\Delta G$ : increment of torque in the rubber compound during vulcanization; $t_{90}$ : optimal vulcanization time; $t_{p}$ : scorch time; $v_{T}$ : cross-link density of vulcanizates; $\Delta v$ : noncovalent cross-link content.

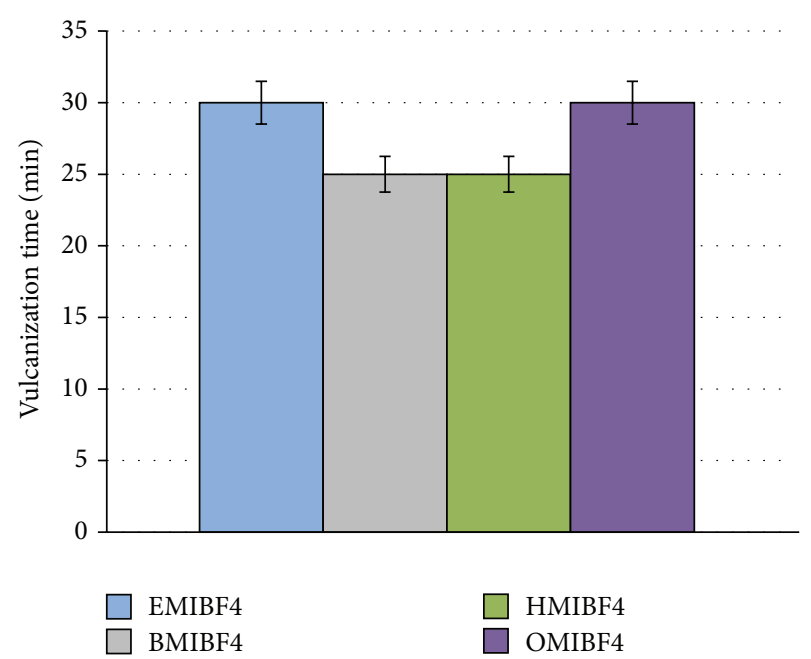

FIGURE 1: Vulcanization time for rubber compounds containing ILs with tetrafluoroborate anions.

In terms of the influence of the IL structure, it was noted that the rubber compounds containing ILs with butyl- and hexyl-chains in the cation and chloride, hexafluorophosphate, or tetrafluoroborate anions showed the shortest vulcanization times (Figures 1 and 2). However, this was not a significant effect from a technological point of view.

ILs caused changes of approximately 20 seconds in the scorch time compared with the time observed for the rubber compound containing only coagent. The shortest scorch time was exhibited by rubber compounds containing $\mathrm{BMIBF}_{4}$ and $\mathrm{HMIBF}_{4}$ (approximately $162 \mathrm{~s}$ ). 


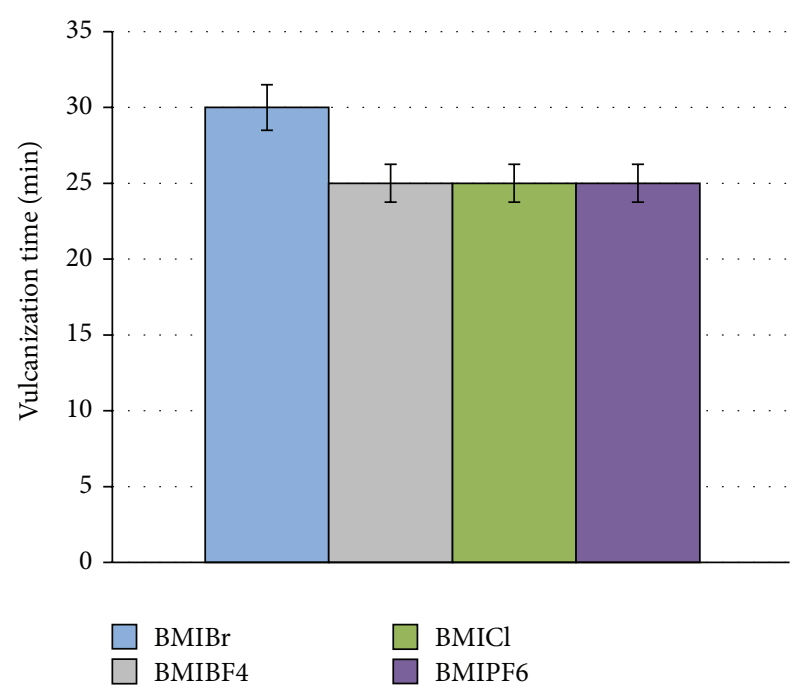

FIGURE 2: Vulcanization time for rubber compounds containing ILs with 1-butyl-3-methylimidazolium cations.

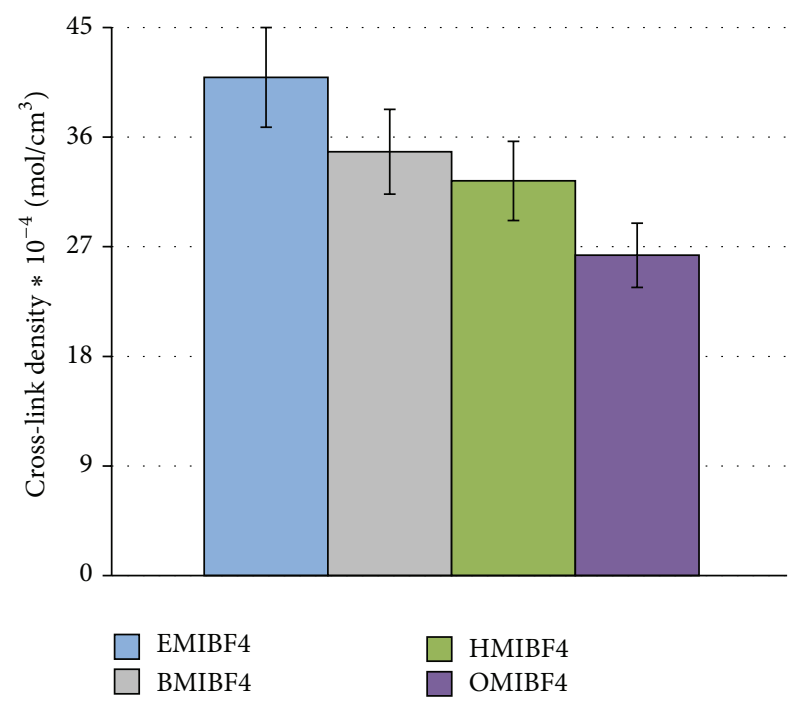

FIGURE 3: Cross-link density of vulcanizates containing ILs with tetrafluoroborate anions.

To estimate the influence of ILs on the vulcanization temperature and the energetic effect of the vulcanization process, a DSC analysis was used. The results are presented in Table 3. ILs had no influence on the vulcanization kinetics. The vulcanization of HNBR is an exothermic process that took place in the temperature range of $155-202^{\circ} \mathrm{C}$ and had an energetic effect of $15.4-23.4 \mathrm{~J} / \mathrm{g}$.

ILs are used as catalysts in interfacial reactions. Crosslinking reactions occur at the interface, so IL application may increase the cross-link density of vulcanizates. The effect of ILs on the cross-link density and on the content of noncovalent cross-links in the elastomer network is presented in Table 2 and Figures 3 and 4.

ILs considerably increased the cross-link density in comparison with the reference HNBR vulcanizate. Only
TABLE 3: Vulcanization temperature and energetic effect of vulcanization determined by DSC.

\begin{tabular}{lccc}
\hline ILs & $\begin{array}{c}\text { Vulcanization } \\
\text { temperature } \\
\text { range }\left({ }^{\circ} \mathrm{C}\right)\end{array}$ & $\begin{array}{c}\text { Temperature of } \\
\text { vulcanization } \\
\text { peak }\left({ }^{\circ} \mathrm{C}\right)\end{array}$ & $\begin{array}{c}\text { Energetic effect } \\
\text { of vulcanization } \\
(\mathrm{J} / \mathrm{g})\end{array}$ \\
\hline- & $161-201$ & 184 & 21.8 \\
$\mathrm{AMIBr}$ & $156-202$ & 183 & 23.4 \\
$\mathrm{BMIBr}$ & $161-197$ & 182 & 15.4 \\
$\mathrm{BMICl}$ & $155-195$ & 180 & 16.5 \\
$\mathrm{EMIBF}_{4}$ & $160-201$ & 185 & 20.9 \\
$\mathrm{BMIBF}_{4}$ & $160-201$ & 185 & 21.0 \\
$\mathrm{HMIBF}_{4}$ & $161-201$ & 185 & 21.4 \\
$\mathrm{MOIBF}_{4}$ & $160-202$ & 185 & 20.1 \\
$\mathrm{BMIPF}_{6}$ & $161-196$ & 186 & 21.9 \\
\hline
\end{tabular}

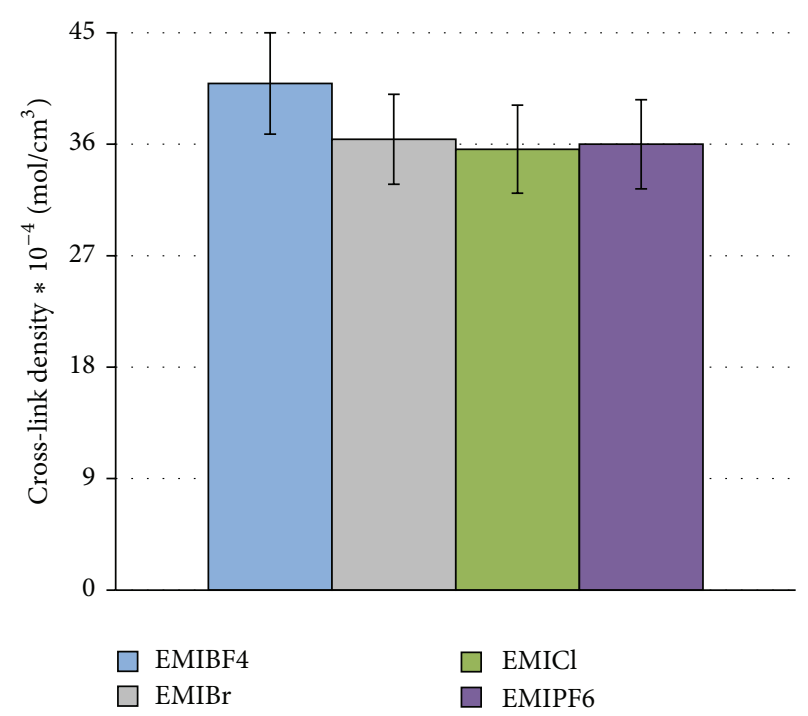

FIGURE 4: Cross-link density of vulcanizates containing ILs with 1ethyl-3-methylimidazolium cations.

ILs with 1-allyl-3-methylimidazolium cations decreased the vulcanizates cross-link density. These ILs could most likely promote the ionic decomposition of part of the dicumyl peroxide, deteriorating the cross-linking efficiency.

Based on vulcanizates containing tetrafluoroborates, the effect of the IL cation structure was studied (Figure 3). The cross-link density of vulcanizates increased with the length of alkyl chains attached to the imidazolium ring in the IL cation. Similar results were obtained for rubber compounds containing hexafluorophosphates.

In terms of the influence of IL anions, the highest cross-link density was obtained for vulcanizates containing tetrafluoroborates; the influence of the other anions was negligible (Figure 4).

The application of a coagent resulted in the formation of noncovalent cross-links in the elastomer network; the crosslink content was approximately $10 \%$. These were ionic crosslinks, which decomposed when the samples were treated with ammonia vapor. Because of their ionic character, most of the 


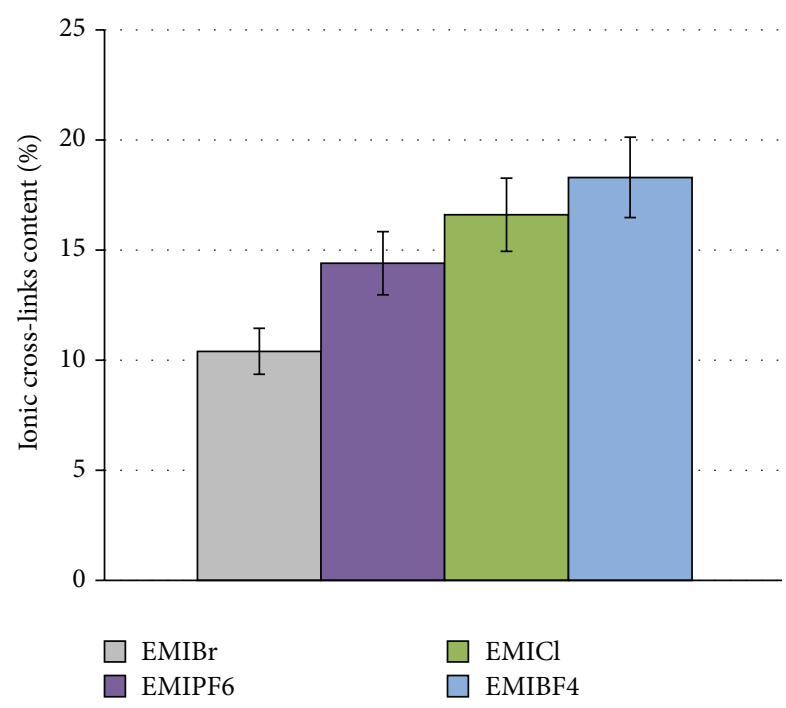

FIGURE 5: Ionic cross-link content in vulcanizates containing ILs with 1-ethyl-3-methylimidazolium cations.

examined ILs increased the content of ionic cross-links in the vulcanizates, up to $18 \%$ in the case of tetrafluoroborates. Another reason for the increased number of cross-links could be more the homogeneous dispersion of coagent particles in the elastomer containing IL, which leads to better accessibility of the coagent functional groups for interactions with the elastomer and a higher activity of the coagent in the cross-linking process. The increase in the number of ionic cross-links is important because the cross-links are able to rearrange inside the elastomer network upon external deformation of the vulcanizate, resulting in an improvement in the tensile strength. The lowest activity was observed for bromides (no influence on the ionic cross-link content) or ILs containing 1-allyl-3-methylimidazolium cations (decrease in the ionic cross-link content by $2 \%$ compared with the reference vulcanizate) (Figure 5).

3.2. Mechanical Properties of Vulcanizates. Having established the influence of ILs on the vulcanization process and on the cross-link density of vulcanizates, we then examined their mechanical properties. The results are given in Table 4.

HNBR vulcanizate containing only coagent had a tensile strength of approximately $10.1 \mathrm{MPa}$ and an elongation at break of 573\%. ILs did not considerably affect the vulcanizate tensile strength or the elongation at break. The highest tensile strength, approximately $12 \mathrm{MPa}$, was obtained for vulcanizates containing 1-methyl-3-butylimidazolium bromide, tetrafluoroborate, or hexafluorophosphate, whereas the lowest tensile parameters were achieved in the presence of ILs with 1-allyl-3-methylimidazolium cations. Similar effects were observed for the cross-link density and the ionic crosslink content of the vulcanizates.

The application of ILs increased the stress relaxation rates of the vulcanizates at the first stage of the stress relaxation process (Table 5). The first stage of stress relaxation was characterized by a rapid rate $\left(n_{1}\right)$, which slowed with time.
TABLE 4: Mechanical properties of HNBR vulcanizates containing ILs.

\begin{tabular}{lcc}
\hline ILs & TS (MPa) & EB (\%) \\
\hline- & 10.1 & 573 \\
AMIBr & 9.0 & 594 \\
EMIBr & 12.0 & 527 \\
BMIBr & 12.0 & 532 \\
AMICl & 8.8 & 609 \\
EMICl & 11.8 & 560 \\
BMICl & 10.9 & 562 \\
HMICl & 11.4 & 566 \\
EMIBF $_{4}$ & 11.9 & 514 \\
BMIBF $_{4}$ & 12.5 & 537 \\
HMIBF $_{4}$ & 12.0 & 549 \\
MOIBF $_{4}$ & 12.3 & 586 \\
EMIPF $_{6}$ & 11.1 & 524 \\
BMIPF $_{6}$ & 12.3 & 525 \\
HMIPF $_{6}$ & 11.8 & 556 \\
\hline S $_{4}$ & &
\end{tabular}

TS: tensile strength; EB: elongation at break, the standard deviation for TS $1.5 \mathrm{MPa}, \mathrm{EB} 25 \%$.

TABLE 5: Stress relaxation rates of HNBR vulcanizates containing ILs.

\begin{tabular}{lccc}
\hline ILs & $n_{1} * 10^{-3}\left(\mathrm{~s}^{-1}\right)$ & $n_{2} * 10^{-3}\left(\mathrm{~s}^{-1}\right)$ & $n_{3} * 10^{-3}\left(\mathrm{~s}^{-1}\right)$ \\
\hline- & 164 & 63 & 38 \\
EMIBr & 188 & 65 & 24 \\
EMICl & 183 & 70 & 26 \\
EMIBF $_{4}$ & 191 & 69 & 45 \\
EMIPF $_{6}$ & 175 & 80 & 37 \\
\hline
\end{tabular}

$n_{1}, n_{2}$, and $n_{3}$ : rates of stress relaxation for the time intervals $0-10 \mathrm{~s}, 10-100 \mathrm{~s}$, and $100-1000 \mathrm{~s}$, respectively, the standard deviation $10 \mathrm{~s}^{-1}$.

The second stage had a relatively uniform rate $\left(n_{2}\right)$. The application of hexafluorophosphate also increased the stress relaxation rate in the second and third stage of the stress relaxation process.

These results confirm that the tensile strength improvement of the vulcanizates is also partially caused by the increase of the vulcanizates stress relaxation ability. The considerable chain slippage and reformation of ionic bonds in the elastomer network under external stress contribute to the increase in the vulcanizate tensile strength.

3.3. Coagent Dispersion in the Elastomer. The aim of the IL application was to improve the dispersion of HTA/MMA particles in the elastomer matrix. The homogeneous dispersion of coagent particles is crucial for maximizing the activity of the coagent in the cross-linking process. Agglomeration decreases the specific surface area of the coagent and, as a result, the interphase between the particles and elastomer chains. SEM images of the vulcanizate surfaces were taken to directly examine the dispersion of coagent particles in the elastomer. These results are presented in Figures 6(a)-6(e).

HTA/MMA particles showed a high ability to agglomerate in the elastomer. They formed agglomerates several 


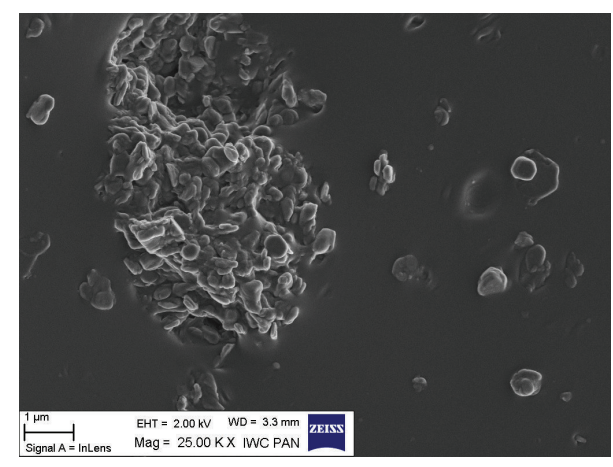

(a)

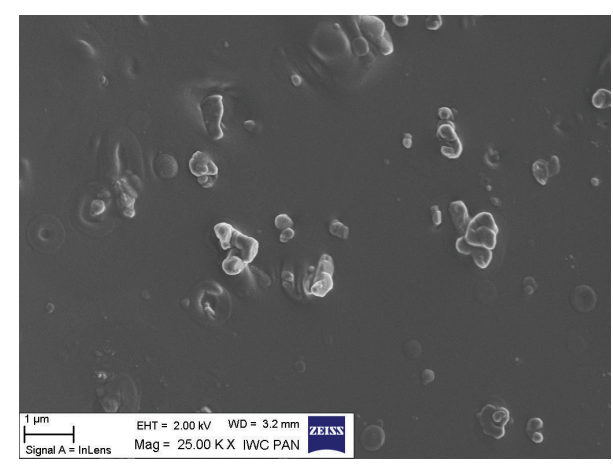

(c)

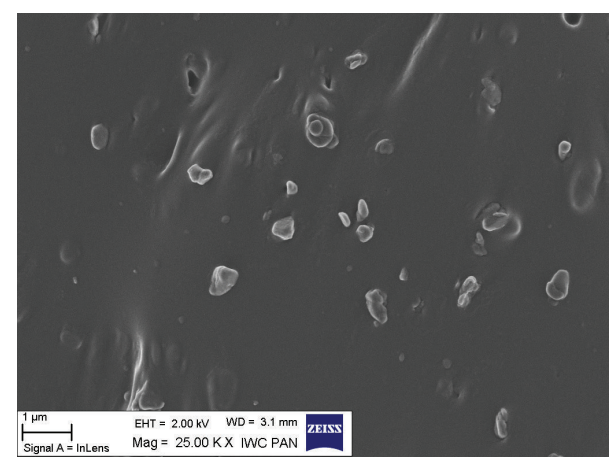

(b)

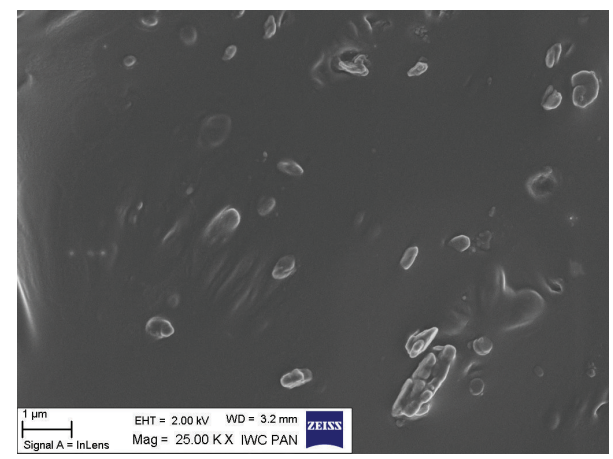

(d)

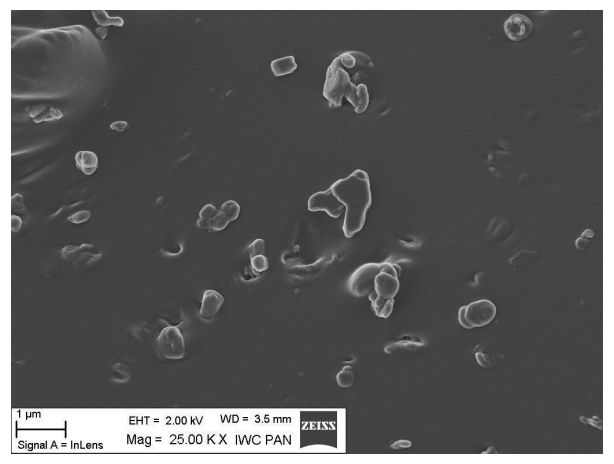

(e)

FIgURE 6: SEM images of vulcanizates containing HTA/MMA: (a) without IL, (b) with BMIBr, (c) with BMIBF , $_{4}(\mathrm{~d})$ with BMICl, (e) and with $\mathrm{BMIPF}_{6}$.

micrometers in size, which were surrounded with elastomer film (Figure 6(a)). Assuming that the coagent particles diffuse through the elastomer matrix and react with elastomer chains, forming ionic cross-links, their agglomeration in the elastomer decreases the activity of the coagent.

The dispersion of coagent particles in the presence of ILs containing 1-butyl-3-methylimidazolium cation is presented in Figures 6(b)-6(e). It follows that ILs significantly improved the dispersion of HTA/MMA particles in the elastomer. The particles created small agglomerates, approximately $0.5-1 \mu \mathrm{m}$ in size, which were homogeneously dispersed in the elastomer and tightly bound to the elastomer matrix. Therefore, alkylimidazolium salts seem to be active dispersing agents of hydrotalcite and can be applied to improve the dispersion of HTA used both as a coagent and a filler for HNBR elastomers.
3.4. Resistance of Vulcanizates to Weather Aging. Having established the effect of ILs on the dispersion of coagents in the elastomer, we then examined their influence on vulcanizate resistance to weather aging. Saturated elastomers crosslinked with peroxides usually demonstrate a strong aging resistance. Therefore, the substances chosen to increase the activity of the coagent should not deteriorate the vulcanizate's resistance to weather ageing. The effect of ILs on vulcanizate resistance to weather aging was examined through the changes in the mechanical properties and cross-link density of the vulcanizates.

In Figure 7, the change in elongation at break upon weather aging is given for vulcanizates containing ILs. Weather aging caused the elongation at break to decrease by approximately $100 \%$ in comparison with vulcanizates before 


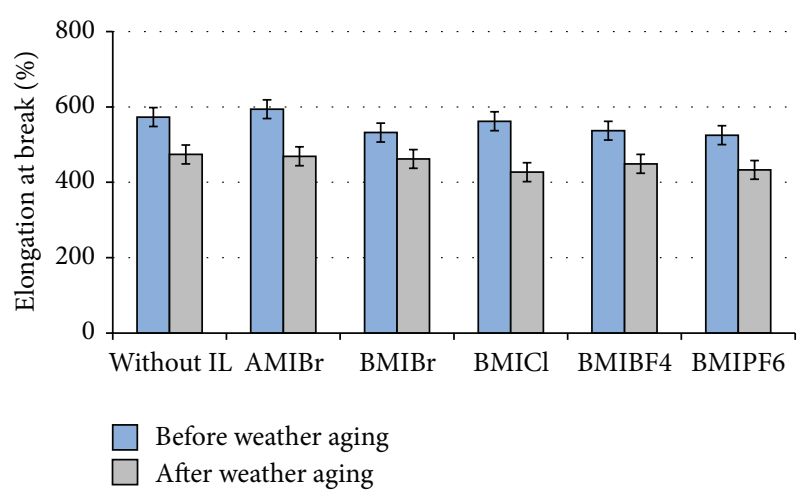

FIGURE 7: Vulcanizate elongation at break after weather aging.

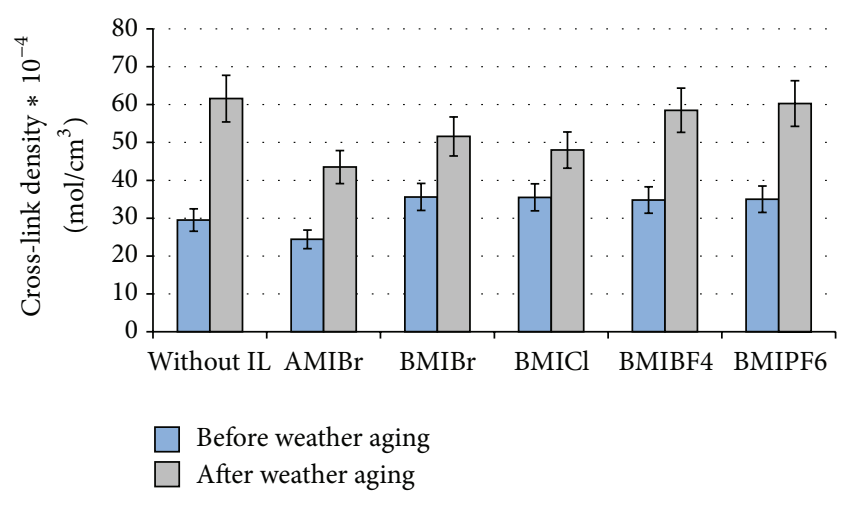

FIGURE 8: Vulcanizate cross-link density after weather aging.

aging process. This change was due to the large increase in the cross-link density of the vulcanizates (Figure 8). It could be concluded that aging factors such as UV radiation and elevated temperature resulted in the further cross-linking of the elastomer. However, the increase in the cross-link density was considerably smaller in the case of vulcanizates containing ILs. Weather aging deteriorated the tensile strength of vulcanizates with ILs, as it did to the vulcanizate with HTA/MMA. The smallest change in tensile strength was achieved for vulcanizates containing $\mathrm{BMIBr}$ and $\mathrm{BMIBF}_{4}$ (Figure 9).

From the results presented in Figures 7-9, it follows that it is difficult to determine the resistance of vulcanizates to weather aging by considering changes in the tensile strength and elongation at break separately. Therefore, to quantitatively estimate the change in the mechanical properties of vulcanizates, the aging factor $K$ was calculated (Table 6).

The aging factor $K$ is a measurement of the changes in the sample deformation energy caused by the weather aging process. The closer to 1 the values of the $K$-factor are, the smaller the changes in the mechanical properties of the vulcanizates from the aging process will be. The aging factor $(K)$ for vulcanizate containing only coagent is 0.30 . The application of ILs increased the values of $K$ considerably. The highest value of $K$ was observed for the vulcanizate containing the $\mathrm{BMIBr}$ and $\mathrm{BMIBF}_{4}$ and was close to 0.7. It can be concluded that ILs provided protection for the HNBR

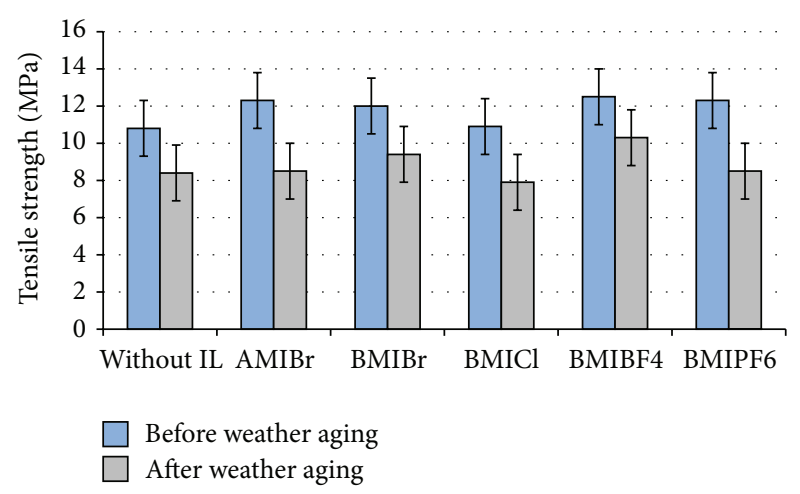

FIGURE 9: Vulcanizate tensile strength after weather aging.

TABLE 6: Weather aging factor $K$ of HNBR vulcanizates containing ILs.

\begin{tabular}{lc}
\hline ILs & $K(-)$ \\
\hline- & 0.30 \\
AMIBr & 0.54 \\
$\mathrm{BMIBr}$ & 0.68 \\
$\mathrm{BMIBF}_{4}$ & 0.72 \\
$\mathrm{BMICl}_{\mathrm{BMIPF}_{6}}$ & 0.55 \\
\hline
\end{tabular}

The standard deviation 0.08 .

against weather aging, which was most likely due to the limitation of the increase in the vulcanizate cross-link density as a function of the aging factors (UV radiation, increased temperature, and humidity).

\section{Conclusions}

Hydrotalcite combined with monoallyl maleate was used as a coagent for peroxide cross-linking of hydrogenated acrylonitrile butadiene elastomers. ILs (alkylimidazolium salts) consisting of different anions (bromides, chlorides, tetrafluoroborates, and hexafluorophosphates) and cations (imidazolium rings with allyl-, ethyl-, butyl-, hexyl-, and octyl- chains) were used to improve the dispersion of the coagent in the elastomer.

HTA/MMA particles agglomerated in the elastomer matrix, forming clusters of particles several micrometers in size. ILs significantly improved the dispersion of the coagent particles in the elastomer, resulting in a higher activity of the coagent in the cross-linking process. The use of ILs yielded vulcanizates with a higher cross-link density and content of noncovalent cross-links compared with vulcanizates containing only coagent. The ILs did not considerably influence the vulcanizate tensile strength. ILs increased the resistance of vulcanizates to weather aging. Further cross-linking of the elastomer containing ILs upon aging was greatly reduced in comparison with the vulcanizate containing only the coagent.

The structure of ILs had an impact on their activity in the cross-linking process and the properties of the vulcanizates. The length of the alkyl chains attached to the imidazolium 
ring in the IL cations was particularly important; the effect of the anion was smaller. Analyzing the results obtained for tetrafluoroborates, it can be concluded that cross-linking density and tensile strength of vulcanizates decreased with increasing alkyl chain lengths.

\section{Acknowledgments}

The authors wish to acknowledge the Polish Ministry of Science and Higher Education and the National Center for Research and Development for supporting this research.

\section{References}

[1] R. D. Rogers and K. R. Seddon, "Ionic Liquids-solvents of the Future?” Science, vol. 302, no. 5646, pp. 792-793, 2003.

[2] P. Wasserscheid and T. Welton, Ionic Liquids in Synthesis, WileyVCH, New York, NY, USA, 2008.

[3] J. Pernak, A. Czepukowicz, and R. Pozniak, "New ionic liquids and their antielectrostatic properties," Industrial \& Engineering Chemistry Research, vol. 40, pp. 2379-2383, 2001.

[4] M. J. Earle, J. M. S. S. Esperança, M. A. Gilea et al., "The distillation and volatility of ionic liquids," Nature, vol. 439, no. 7078, pp. 831-834, 2006.

[5] R. Vijayaraghavan and D. R. MacFarlane, "Living cationic polymerisation of styrene in an ionic liquid," Chemical Communications, vol. 10, no. 6, pp. 700-701, 2004.

[6] N. Sun, M. Rahman, Y. Qin, M. L. Maxim, H. Rodríguez, and R. D. Rogers, "Complete dissolution and partial delignification of wood in the ionic liquid 1-ethyl-3-methylimidazolium acetate," Green Chemistry, vol. 11, no. 5, pp. 646-655, 2009.

[7] A. Biswas, R. L. Shogren, D. G. Stevenson, J. L. Willett, and P. K. Bhowmik, "Ionic liquids as solvents for biopolymers: acylation of starch and zein protein," Carbohydrate Polymers, vol. 66, no. 4, pp. 546-550, 2006.

[8] A. Das, K. W. Stöckelhuber, R. Jurk, J. Fritzsche, M. Klüppel, and G. Heinrich, "Coupling activity of ionic liquids between diene elastomers and multi-walled carbon nanotubes," Carbon, vol. 47, no. 14, pp. 3313-3321, 2009.

[9] M. P. Scott, M. Rahman, and C. S. Brazel, "Application of ionic liquids as low-volatility plasticizers for PMMA," European Polymer Journal, vol. 39, no. 10, pp. 1947-1953, 2003.

[10] Y. Shen, S. Ding, and H. Tang, "Catalyst separation in atom transfer radical polymerization," Progress in Polymer Science, vol. 29, no. 10, pp. 1053-1078, 2004.

[11] P. Kubisa, "Application of ionic liquids as solvents for polymerization processes," Progress in Polymer Science, vol. 29, no. 1, pp. 3-12, 2004.

[12] J. B. Class, "A review of the fundamentals of crosslinking with peroxides," Rubber World, vol. 220, no. 5, pp. 35-39, 1999.

[13] Z. H. Murgic, J. Jelenčić, and L. Murgić, "The mechanism of triallylcyanurate as a coagent in EPDM peroxide vulcanization," Polymer Engineering and Science, vol. 38, no. 4, pp. 689-692, 1998.

[14] R. E. Drake, J. J. Holliday, and M. S. Costello, "Use of polybutadiene coagents in peroxide cured elastomers for wire and cable," Rubber World, vol. 213, no. 3, pp. 22-30, 1995.

[15] M. M. Alvarez-Grima, A. G. Talma, R. N. Datta, and J. W. M. Noordermeer, "New concept of Co-agents for Scorch delay and property improvement in peroxide vulcanization," Rubber Chemistry and Technology, vol. 79, no. 4, pp. 694-711, 2006.
[16] H. G. Dikland, L. van der Does, and A. Bantjes, "FT-IR spectroscopy, a major tool for the analysis of peroxide vulcanization processes in the presence of coagents. I. Mechanism of EPM peroxide vulcanization with aromatic bis(allyl)esters as coagents," Rubber Chemistry and Technology, vol. 66, no. 2, pp. 196-211, 1993.

[17] M. Maciejewska, A. Krzywania-Kaliszewska, and M. Zaborski, "Hydrotalcite/unsaturated carboxylic acid systems as coagents in ethylene-propylene copolymer vulcanization," American Journal of Materials Science, vol. 1, no. 2, pp. 81-88, 2011.

[18] Y. Lu, L. Liu, M. Tian, H. Geng, and L. Zhang, "Study on mechanical properties of elastomers reinforced by zinc dimethacrylate," European Polymer Journal, vol. 41, no. 3, pp. 589-598, 2005.

[19] M. Hirao, K. Ito, and H. Ohno, "Preparation and polymerization of new organic molten salts; $\mathrm{N}$-alkylimidazolium salt derivatives," Electrochimica Acta, vol. 45, no. 8, pp. 1291-1294, 2000.

[20] Y. D. Lei, Z. H. Tang, B. C. Guo, L. X. Zhu, and D. M. Jia, "Synthesis of novel functional liquid and its application as a modifier in SBR/silica composites," eXPRESS Polymer Letters, vol. 4, no. 11, pp. 692-703, 2010.

[21] M. Przybyszewska and M. Zaborski, "Effect of ionic liquids and surfactants on zinc oxide nanoparticle activity in crosslinking of acrylonitrile butadiene elastomer," Journal of Applied Polymer Science, vol. 116, no. 1, pp. 155-164, 2010.

[22] M. Maciejewska, M. Zaborski, A. Krzywania-Kaliszewska et al., "Mineral oxides and layered minerals in combination with itaconic acid as coagents for peroxide crosslinking of hydrogenated acrylonitrile-butadiene elastomer," Journal of Chromatography A, vol. 15, no. 5, pp. 414-423, 2012.

[23] P. J. Flory and J. Rehner, "Statistical mechanics of cross-linked polymer networks II. Swelling," The Journal of Chemical Physics, vol. 11, no. 11, pp. 521-526, 1943. 

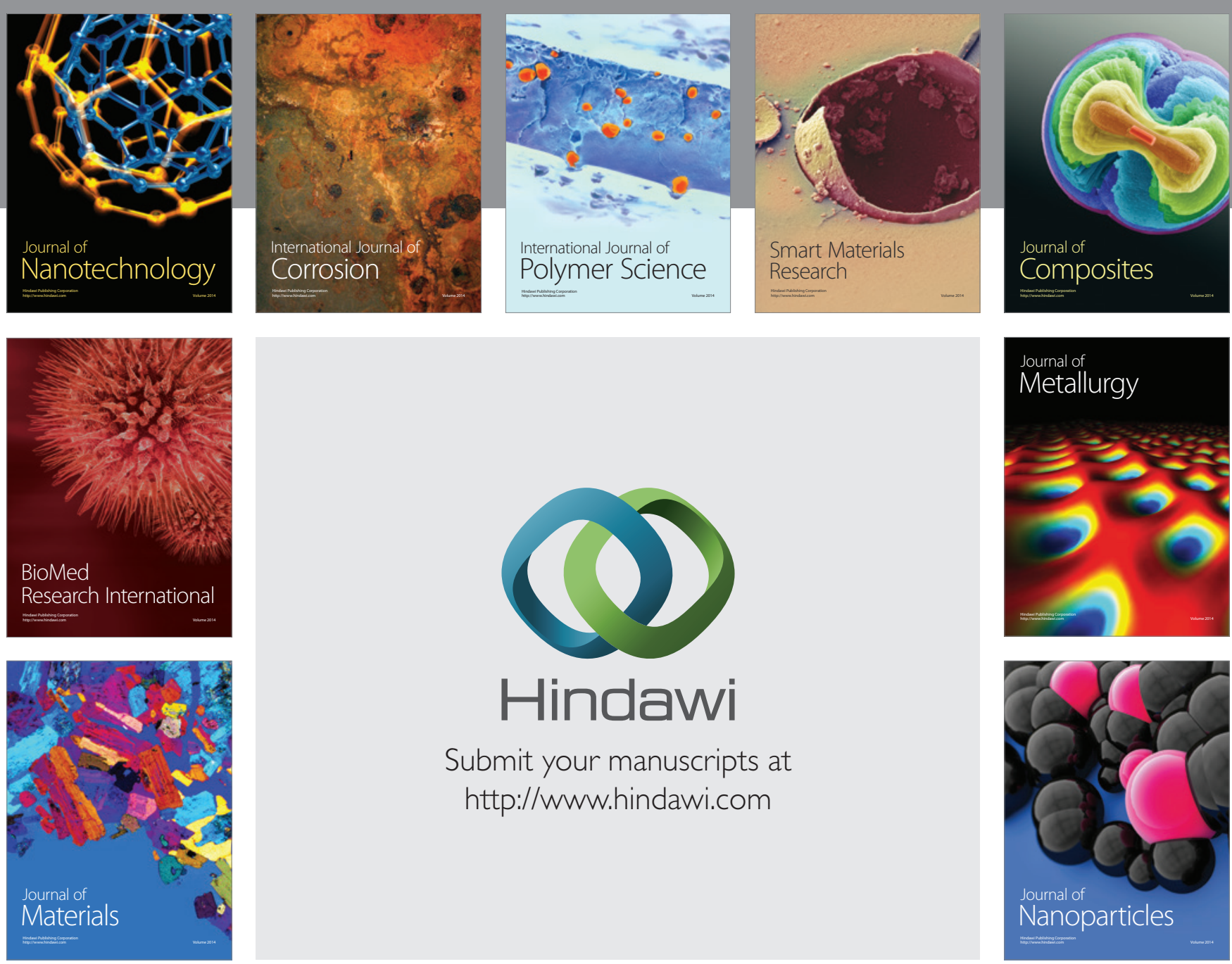

Submit your manuscripts at http://www.hindawi.com
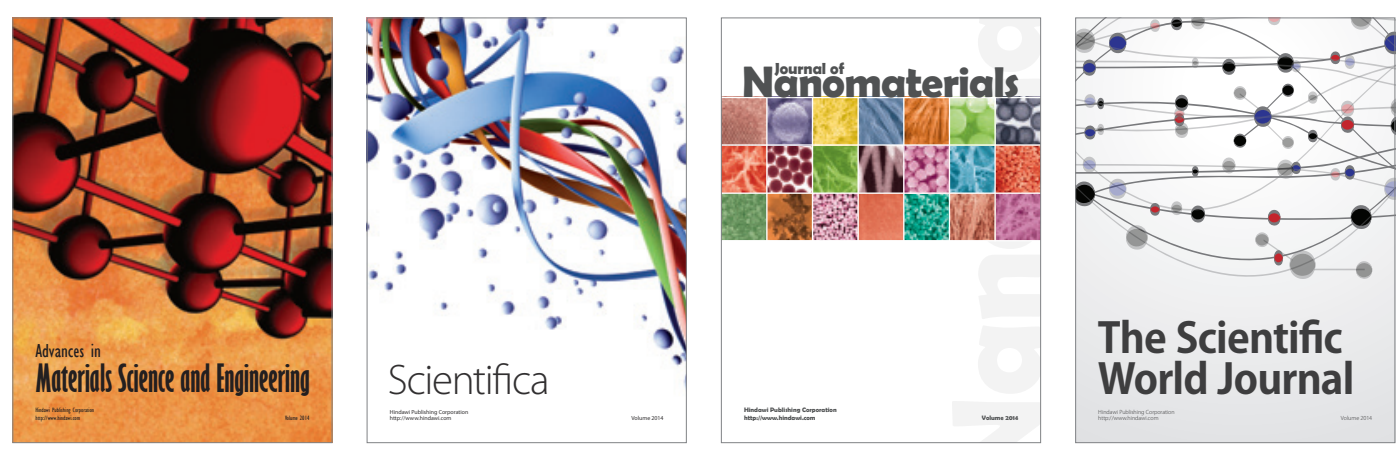

\section{The Scientific World Journal}
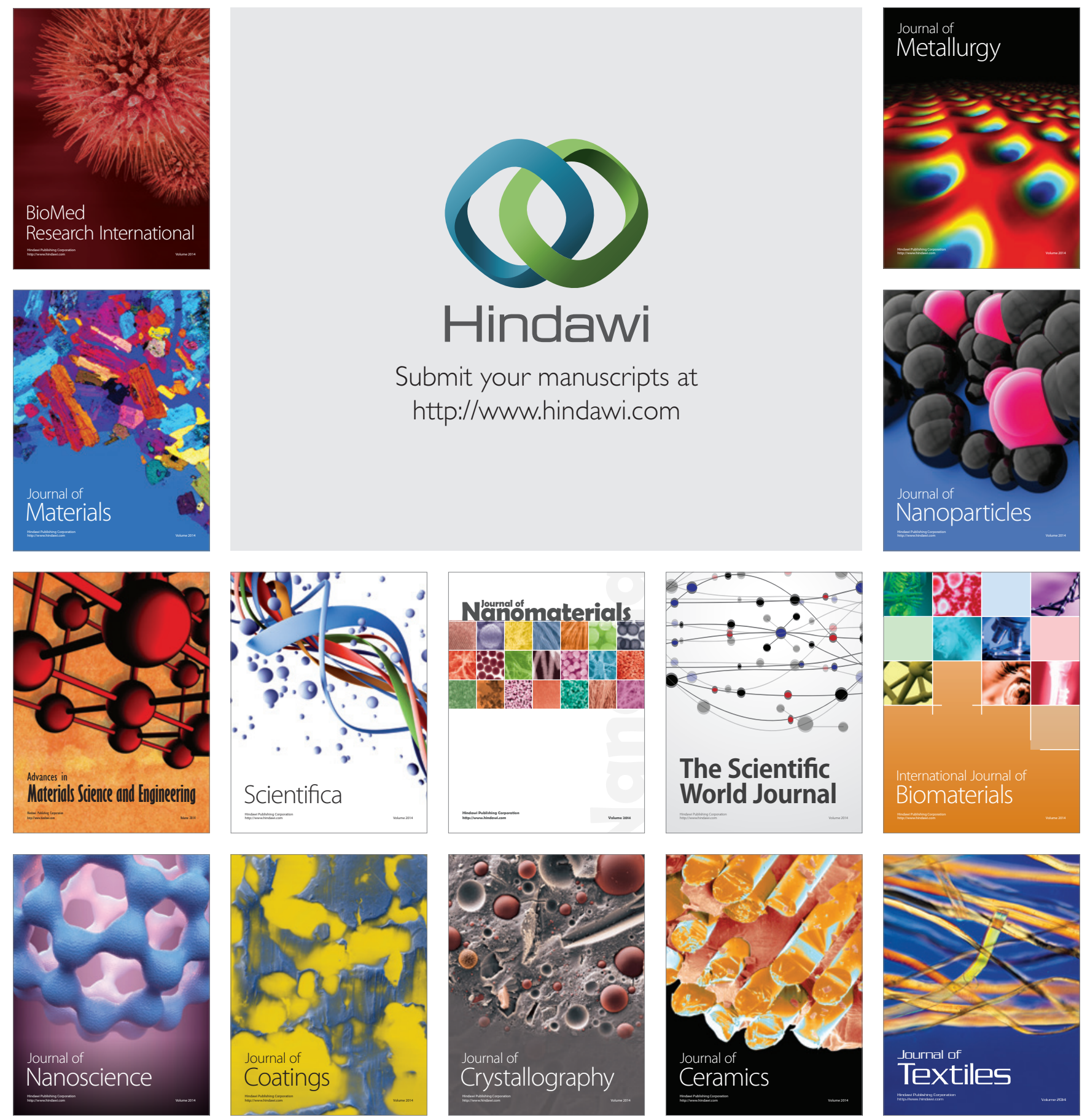